\title{
High-resolution 3D volumetric contrast-enhanced MR angiography with a blood pool agent (ferumoxytol) for diagnostic evaluation of pediatric brain arteriovenous malformations
}

\author{
*Michael Iv, MD,' Omar Choudhri, MD,' Robert L. Dodd, MD, PhD,1 \\ Shreyas S. Vasanawala, MD, PhD, ${ }^{1,2}$ Marcus T. Alley, PhD, ${ }^{3}$ Michael Moseley, PhD, ${ }^{3}$ \\ Samantha J. Holdsworth, PhD, ${ }^{3}$ Gerald Grant, MD, Samuel Cheshier, MD, PhD, ${ }^{4}$ and \\ Kristen W. Yeom, MD²
}

1Department of Radiology, Stanford University Medical Center, Stanford; 'Department of Radiology, Lucile Packard Children's Hospital, Palo Alto; ${ }^{3}$ Richard M. Lucas Center for Imaging, Stanford University, Stanford; and ${ }^{2}$ Division of Pediatric Neurosurgery, Lucile Packard Children's Hospital, Palo Alto, California

OBJECTIVE Patients with brain arteriovenous malformations (AVMs) often require repeat imaging with MRI or MR angiography (MRA), CT angiography (CTA), and digital subtraction angiography (DSA). The ideal imaging modality provides excellent vascular visualization without incurring added risks, such as radiation exposure. The purpose of this study is to evaluate the performance of ferumoxytol-enhanced MRA using a high-resolution 3D volumetric sequence (fe-SPGR) for visualizing and grading pediatric brain AVMs in comparison with CTA and DSA, which is the current imaging gold standard.

METHODS In this retrospective cohort study, 21 patients with AVMs evaluated by fe-SPGR, CTA, and DSA between April 2014 and August 2017 were included. Two experienced raters graded AVMs using Spetzler-Martin criteria on all imaging studies. Lesion conspicuity (LC) and diagnostic confidence (DC) were assessed using a 5-point Likert scale, and interrater agreement was determined. The Kruskal-Wallis test was performed to assess the raters' grades and scores of $\mathrm{LC}$ and $\mathrm{DC}$, with subsequent post hoc pairwise comparisons to assess for statistically significant differences between pairs of groups at $p<0.05$.

RESULTS Assigned Spetzler-Martin grades for AVMs on DSA, fe-SPGR, and CTA were not significantly different ( $p$ $=0.991)$. $L C$ and DC scores were higher with fe-SPGR than with CTA $(p<0.05)$. A significant difference in LC scores was found between CTA and fe-SPGR $(p<0.001)$ and CTA and DSA $(p<0.001)$ but not between fe-SPGR and DSA ( $p$ $=0.146)$. A significant difference in DC scores was found among DSA, fe-SPGR, and CTA $(p<0.001)$ and between all pairs of the groups $(p<0.05)$. Interrater agreement was good to very good for all image groups $(\kappa=0.77-1.0, p<0.001)$. CONCLUSIONS Fe-SPGR performed robustly in the diagnostic evaluation of brain AVMs, with improved visual depiction of AVMs compared with CTA and comparable Spetzler-Martin grading relative to CTA and DSA.

https://thejns.org/doi/abs/10.3171/2018.3.PEDS17723

KEYWORDS arteriovenous malformation; ferumoxytol; high-resolution MRI; MR angiography; vascular disorders

$\mathrm{B}$ RAIN arteriovenous malformations (AVMs) are congenital vascular lesions that are composed of a tangled network of dilated arteries and veins that do not have a normal intervening capillary bed and demonstrate early arteriovenous shunting. These lesions occur in $0.01 \%$ to $0.52 \%$ of individuals in the general population and carry a life-long bleeding risk of $1.5 \%$ to $4 \%$ per year. ${ }^{13,14,39}$ In the pediatric population, AVMs account for $35 \%$ to $55 \%$ of intracranial hemorrhage, with the rate of hemorrhage often dependent on multiple risk factors, such

ABBREVIATIONS ASL = arterial spin labeling; AVM = arteriovenous malformation; CE-MRA = contrast-enhanced MRA; CTA = CT angiography; DAP = dose area product; $\mathrm{DC}=$ diagnostic confidence; DLP = dose length product; DSA = digital subtraction angiography; fe-SPGR = ferumoxytol-enhanced spoiled gradient recalled acquisition echo; fMRI = functional MRI; LC = lesion conspicuity; MRA = MR angiography; TOF = time of flight.

SUBMITTED December 18, 2017. ACCEPTED March 14, 2018

INCLUDE WHEN CITING Published online June 8, 2018; DOI: 10.3171/2018.3.PEDS17723.

* S.C. and K.W.Y. contributed equally to this article and share senior authorship. 
as AVM location, episodes of prior hemorrhage, venous drainage patterns, and associated peri-nidal aneurysms. ${ }^{32}$ Due to the high morbidity and mortality associated with ruptured and bleeding AVMs, early treatment is often indicated. Treatment options, which are influenced by the Spetzler-Martin grade of the AVM ${ }^{40}$ include endovascular embolization, stereotactic radiosurgery, and/or resection.

Despite treatment, the recurrence rate of AVMs in the pediatric population has been reported in up to $5 \%$ of cases, occurring as far out as 16 years after completion of initial therapy. ${ }^{3}$ Consequently, imaging is often performed pre- and post-therapy. Imaging modalities of choice for evaluating AVMs include CT angiography (CTA), MR angiography (MRA), and digital subtraction angiography (DSA), the latter representing the current gold standard for evaluating AVMs because of its high spatial and temporal resolution. However, DSA is an invasive procedure that confers neurological procedure risks $(0.30 \%$ to $2.63 \%)$, requires sedation or general anesthesia in children, and exposes patients to radiation. ${ }^{3,39}$ Similarly, radiation exposure is associated with CTA. To minimize these risks, several MRI techniques, including $3 \mathrm{D}^{15,23,42}$ and $4 \mathrm{D}^{5,13,14,17,20,39}$ time-of-flight (TOF) MRA and contrast-enhanced MRA (CE-MRA), have been used.

Ferumoxytol (Feraheme, AMI-7228, AMAG Pharmaceuticals, Inc.), an ultrasmall superparamagnetic iron oxide nanoparticle, has been extensively used as a blood pool contrast agent in MRA, with most applications described in adults outside of the central nervous system. ${ }^{8,9,12,36,38}$ However, ferumoxytol has increasingly shown utility for the evaluation of cerebrovascular lesions., ${ }^{4,7}$ Ferumoxytol's use as an MR contrast agent is currently off-label, although it was approved by the US FDA in 2009 for the treatment of iron deficiency anemia in adult patients with chronic kidney disease. ${ }^{24}$ It has a half-life of approximately 14 hours in humans and remains in the intravascular space early after injection, which are properties of an excellent blood pool agent. ${ }^{19}$

In the era of low-risk, noninvasive imaging, the purpose of our study was to evaluate the performance of contrastenhanced MR angiography (CE-MRA) using a ferumoxytol-enhanced 3D volumetric spoiled gradient recalled echo (fe-SPGR) sequence for visualizing and grading pediatric brain AVMs in comparison to CTA and DSA.

\section{Methods \\ Patient Population}

This is an IRB-approved retrospective cohort study at a single academic institution consisting of children and young adults with AVMs. As this study involved the collection of clinical and imaging data obtained as part of past routine patient care, informed consent was not required by our IRB. Patients with a diagnosis of AVM (independent of prior treatment) who underwent MRI with high-resolution 3D volumetric CE-MRA using ferumoxytol-enhanced SPGR (fe-SPGR) between April 2014 and August 2017 were identified through our picture archiving and communication system (PACS) imaging database by keyword search criteria. Specific keywords were "arteriovenous malformation," "AVM," "ferumoxytol," and
"Feraheme." This search yielded a total of 28 patients. Of these patients, only those who had undergone CTA and DSA and who did not have any intervening treatment between any of the 3 imaging studies were included. After final exclusion, 21 patients were included in the study. The beginning of the study period denoted the time that our institution began using ferumoxytol routinely for clinical evaluation of cerebrovascular lesions in light of our prior clinical experiences of ferumoxytol-enhanced MRI showing improved visualization of vascular lesions outside of the central nervous system. ${ }^{31,35}$ Sedation information was obtained through the electronic medical record.

\section{Imaging}

CTA was performed using Lightspeed 16 and Lightspeed VCT scanners (GE Healthcare) with the following scan parameters: $1.25-\mathrm{mm}$ section thickness, 100-120 $\mathrm{kVp}, 300-600 \mathrm{~mA}$. The scanning was triggered by the CT technologist based on contrast enhancement of the aortic arch following the intravenous administration of iohexol with a concentration of $350 \mathrm{mg} / \mathrm{ml}$ (Omnipaque 350 , GE Healthcare) at a rate of 4 to $5 \mathrm{ml} / \mathrm{sec}$. All MR images were obtained using a $3 \mathrm{~T}$ scanner (Discovery 750 , GE Healthcare) equipped with a standard 8-channel head coil, and all digital subtraction angiograms were obtained using a Siemens Artis zee biplane system. Acquired MRI sequences in our vascular protocol during the study period included T1- and T2-weighted spin echo, diffusionweighted imaging, gradient recalled echo, fluid-attenuated inversion recovery sequences in addition to arterial spin labeling (ASL), noncontrast 3D TOF MRA, and 3D CEMRA using fe-SPGR. Imaging parameters for fe-SPGR were as follows: TR $4 \mathrm{msec}$, TE $1 \mathrm{msec}$, slice thickness 1 $\mathrm{mm}$, slice spacing $0.5 \mathrm{~mm}$, matrix $416 \times 416$, field of view 24-26 cm, inversion time (performed for fat suppression) $12.6 \mathrm{msec}$, flip angle $15^{\circ}$, receiver bandwidth $62.5 \mathrm{kHz}$, and number of excitations 1. The SPGR sequence was designed to operate with minimum repetition and echo times, and the scan time was optimized by not acquiring the corners of ky-kz space, producing an acquisition time of approximately 5 minutes and 46 seconds. These parameters allow for excellent visualization of the vessels and suppression of the brain parenchyma. In contrast, our "standard clinical" SPGR, which is more optimized to evaluate the brain parenchyma, has a TR of 6-8 msec and a TE of $3 \mathrm{msec}$. Before SPGR acquisition, a single dose of ferumoxytol $(3 \mathrm{mg} / \mathrm{kg}$ bodyweight diluted in normal saline) was administered intravenously over a 10- to 15-minute period, followed immediately by $20 \mathrm{ml}$ of saline flush. Patients were closely monitored for allergic and anaphylactic reactions to the drug with subjective and objective assessment, including vital sign and neurological checks.

\section{Radiation Dose Determination}

Dosimetry-related data for CTA and DSA studies were obtained through a dose-tracking system, DoseWatch (version 2.2.1, GE Healthcare). The effective dose was calculated by multiplying the dose length product (DLP) $(\mathrm{mGy} \times \mathrm{cm})$ by the dose conversion factor $(\mathrm{mSv} / \mathrm{mGy} \times \mathrm{cm})$ for CTA and the dose area product (DAP) $\left(\mathrm{Gy} \times \mathrm{cm}^{2}\right)$ by 
the dose conversion factor $\left(\mathrm{mSv} / \mathrm{Gy} \times \mathrm{cm}^{2}\right)$ for DSA. ${ }^{27}$ The conversion factors used for head and head and neck CTA were 0.0021 and $0.00345 \mathrm{mSv} / \mathrm{mGy} \times \mathrm{cm}$, respectively. ${ }^{30}$ The dose conversion factor used for cerebral DSA was $0.056 \mathrm{mSv} / \mathrm{Gy} \times \mathrm{cm}^{2}{ }^{26}$

\section{Grading of AVMs}

Two experienced and board-certified diagnostic neuroradiologists blindly and independently graded AVMs using Spetzler-Martin criteria ${ }^{40}$ on all imaging data sets: fe-SPGR, CTA, and DSA (Fig. 1). If one of the SpetzlerMartin features (nidus size, location relative to eloquence of the adjacent brain, venous drainage) could not be adequately assessed, a grade was not assigned. Each rater also identified the presence of any peri-nidal and intranidal aneurysms. In addition, each reader assigned a score for lesion conspicuity (LC; determined based on 2 factors: how prominently the AVM stood out from the background parenchyma and how easy it was to differentiate between arteries and veins) and diagnostic confidence (DC; defined as the degree of confidence that an AVM on an image was truly present or not present). Scores of LC and DC were assigned using a 5-point Likert scale (1, poor; 2 , below average; 3 , fair; 4 , good; 5 , excellent). As DSA is routinely performed and the images are officially read by neurointerventionalists at our institution, we enlisted 2 experienced neurointerventionalists to independently grade AVMs using the same Spetzler-Martin criteria for DSA. Scores from the 2 diagnostic neuroradiologists were then compared to those from the 2 neurointerventionalists to ensure that there was no significant difference in DSA readings.

\section{Statistical Analysis}

Interrater agreement between the readers was assessed with Fleiss' generalized kappa coefficient $(\kappa)$, utilizing the following interpretation model of $\kappa:<0.20$ poor, $0.21-0.40$ fair, 0.41-0.60 moderate, 0.61-0.80 good, and 0.81-1.00 very good. ${ }^{1}$ The nonparametric Kruskal-Wallis test was performed to assess the raters' scores of Spetzler-Martin grades, LC, and DC as well as to compare Spetzler-Martin grades on DSA between diagnostic neuroradiologists and neurointerventionalists. Post hoc pairwise comparisons were subsequently performed using the Dunn test with further Benjamini-Hochberg false discovery rate correction, to assess for statistically significant differences between pairs of groups at $p<0.05$. Statistical analyses were performed with the publically available statistical software package R (R Foundation for Statistical Computing, http://www.R-project.org).

\section{Results}

Patient demographics, contrast, sedation, and radiation exposure data for each image modality are shown in Table 1 , and the cumulative exposure data during the study period are shown in Table 2. Twenty-one children and young adult patients (12 females, 9 males; mean age \pm SD $13.5 \pm$ 5.0 years, range $4-24$ years) were included in this study. Each patient underwent CTA, fe-SPGR, and DSA. No patients experienced any adverse event related to ferumoxy-
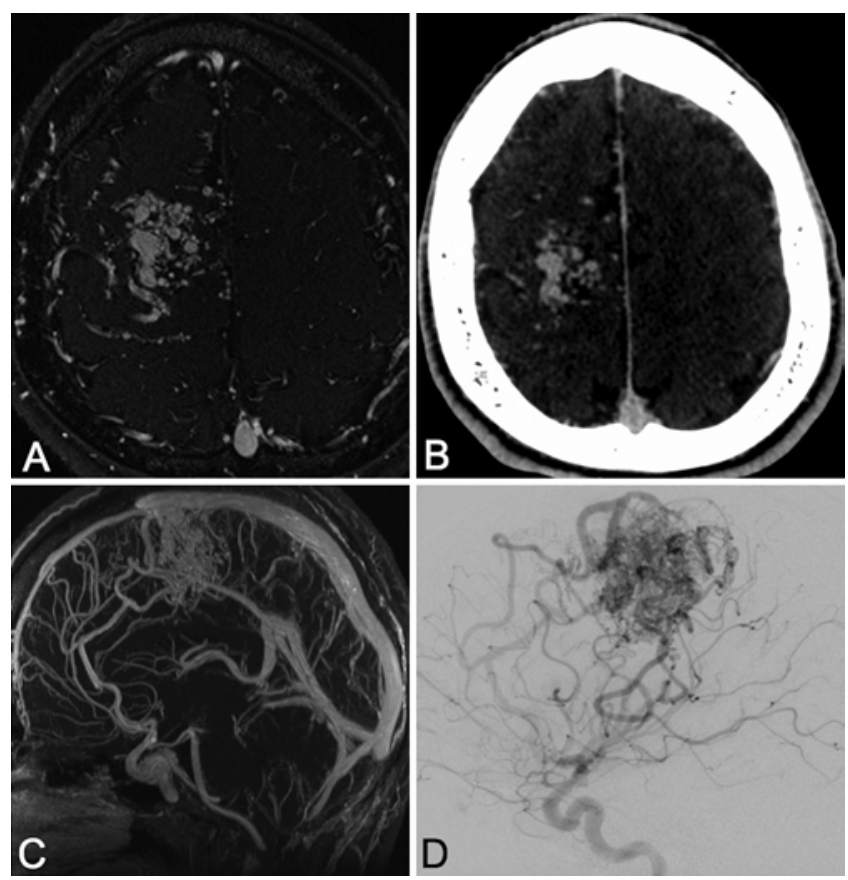

FIG. 1. Images obtained in an 18-year-old male patient with a brain parenchymal AVM. Contrast-enhanced MR angiogram using fe-SPGR (A), CT angiogram (B), maximum intensity projection image from fe-SPGR (C), and late arterial DS angiogram (D) showing a Spetzler-Martin grade II AVM in the right frontal lobe.

tol administration. Twelve patients had a new diagnosis of AVM at the time of imaging, while 9 patients had been previously treated (1 with resection, 5 with embolization, 1 with radiotherapy, and 2 with endovascular embolization and subsequent radiotherapy). Brain AVM locations were as follows: frontal lobe $(n=5)$, temporal lobe $(n=$ $3)$, parietal lobe $(n=3)$, occipital lobe $(n=1)$, deep gray nuclei (basal ganglia or thalamus; $n=4$ ), corpus callosum $(\mathrm{n}=1)$, diffuse/hemispheric $(\mathrm{n}=1)$, cerebellum $(\mathrm{n}=1)$, and brainstem $(\mathrm{n}=2)$.

Figure 2 illustrates the distribution and percentage of AVMs assigned each Spetzler-Martin grade in the 21 patients who underwent CTA, fe-SPGR, and DSA. There was no significant difference between Spetzler-Martin grades assigned between any of the groups using pooled scores from all readers $(\mathrm{p}=0.991)$. A Spetzler-Martin grade was assigned to $100 \%$ of patients for DSA and fe-SPGR, with very good agreement between all raters (DSA: $\kappa=1.0, p<$ 0.001; fe-SPGR: $\kappa=0.94, p<0.001$ ). For CTA, only $81 \%$ of patients were assigned a grade, with very good agreement between readers $(\kappa=0.93, p<0.001)$. Assignment of Spetzler-Martin grades on DSA was not statistically significant between the diagnostic neuroradiologists and neurointerventionalists $(\mathrm{p}>0.99)$.

Figure 3 shows the mean scores of LC and DC on CTA, fe-SPGR, and DSA as determined by the 2 diagnostic neuroradiology readers. Using pooled scores of LC, Kruskal-Wallis testing among the 3 image groups revealed a significant difference $(\mathrm{p}<0.001)$. Post hoc pairwise comparison tests showed significant differences between CTA and fe-SPGR ( $<0.001)$ and between CTA and DSA ( $p$ $<0.001)$. However, there was no significant difference be- 
TABLE 1. Patient demographics, contrast, sedation, and radiation exposure for each image modality

\begin{tabular}{|c|c|c|c|c|c|c|c|c|c|c|c|}
\hline \multirow[b]{2}{*}{$\begin{array}{l}\text { Case } \\
\text { No. }\end{array}$} & \multirow{2}{*}{$\begin{array}{c}\text { Age } \\
\text { (yrs), } \\
\text { Sex }\end{array}$} & \multicolumn{2}{|c|}{ fe-SPGR } & \multicolumn{4}{|c|}{ CTA } & \multicolumn{4}{|c|}{ DSA } \\
\hline & & $\begin{array}{c}\text { Contrast } \\
\text { Amount (ml) }\end{array}$ & Sedation & $\begin{array}{l}\text { Exam } \\
\text { Type }\end{array}$ & Sedation & $\begin{array}{l}\text { DLP Exposure } \\
(\mathrm{mG} \text { yxcm) }\end{array}$ & $\begin{array}{l}\text { Effective Dose } \\
\text { Exposure (mSv) }\end{array}$ & $\begin{array}{l}\text { Exam } \\
\text { Type }\end{array}$ & Sedation & $\begin{array}{l}\text { DAP Exposure } \\
\qquad\left(\mathrm{Gy} \times \mathrm{cm}^{2}\right)\end{array}$ & $\begin{array}{l}\text { Effective Dose } \\
\text { Exposure (mSv) }\end{array}$ \\
\hline 1 & $14, \mathrm{~F}$ & 6.5 & No & $\mathrm{H} \& \mathrm{~N}$ & No & 1063.01 & 3.67 & $D x+T x$ & Yes (GA) & 208.33 & 11.67 \\
\hline 2 & $13, \mathrm{M}$ & 5.0 & No & $\mathrm{H}$ & No & 673.03 & 1.41 & Dx & Yes (GA) & 101.52 & 5.69 \\
\hline 3 & $15, M$ & 6.0 & No & $\mathrm{H}$ & No & 1157.11 & 2.43 & $D x$ & Yes (GA) & 152.31 & 8.53 \\
\hline 4 & $14, \mathrm{~F}$ & 6.1 & No & $\mathrm{H}$ & No & 492.59 & 1.03 & $D x$ & Yes (GA) & 140.19 & 7.85 \\
\hline 5 & $9, \mathrm{~F}$ & 3.2 & No & $\mathrm{H}$ & No & 530.72 & 1.11 & $D x$ & Yes (GA) & 45.78 & 2.56 \\
\hline 6 & $24, F$ & 6.0 & No & $H \& N$ & No & 834.33 & 2.88 & $D x$ & Yes (GA) & 56.17 & 3.15 \\
\hline 7 & $9, \mathrm{~F}$ & 3.4 & Yes (GA) & $\mathrm{H} \& \mathrm{~N}$ & No & 898.51 & 3.10 & $D x$ & Yes (CS) & 13.50 & 0.76 \\
\hline 8 & $18, M$ & 12.2 & No & $H \& N$ & No & 802.24 & 2.77 & $D x$ & Yes (GA) & 216.74 & 12.14 \\
\hline 9 & $22, \mathrm{~F}$ & 5.5 & No & $\mathrm{H} \& \mathrm{~N}$ & No & 898.51 & 3.10 & $D x$ & Yes (CS) & 83.87 & 4.70 \\
\hline 10 & $16, F$ & 5.2 & No & $H \& N$ & No & 866.42 & 2.99 & $D x$ & Yes (CS) & 146.70 & 8.22 \\
\hline 11 & $8, F$ & 3.6 & Yes (GA) & $H \& N$ & No & 924.81 & 3.19 & $D x$ & Yes (GA) & 60.59 & 3.39 \\
\hline 12 & $11, \mathrm{~F}$ & 3.9 & No & $H \& N$ & No & 738.06 & 2.55 & $D x$ & Yes (GA) & 103.87 & 5.82 \\
\hline 13 & $16, F$ & 3.4 & No & $H \& N$ & No & 834.33 & 2.88 & $\mathrm{Dx}$ & Yes (GA) & 94.24 & 5.28 \\
\hline 14 & $18, M$ & 12.4 & No & $H \& N$ & No & 802.24 & 2.77 & $D x+T x$ & Yes (GA) & 571.87 & 32.02 \\
\hline 15 & $15, M$ & 11.5 & No & $\mathrm{H} \& \mathrm{~N}$ & No & 834.33 & 2.88 & $\mathrm{Dx}$ & Yes (GA) & 54.03 & 3.03 \\
\hline 16 & $18, F$ & 5.0 & No & $\mathrm{H} \& \mathrm{~N}$ & No & 100.70 & 0.35 & $D x$ & Yes (GA) & 62.20 & 3.48 \\
\hline 17 & $4, \mathrm{M}$ & 3.4 & Yes (GA) & $\mathrm{H}$ & No & 766.22 & 1.61 & $\mathrm{Dx}$ & Yes (GA) & 40.35 & 2.26 \\
\hline 18 & $12, \mathrm{M}$ & 3.3 & Yes (GA) & $\mathrm{H}$ & No & 82.07 & 0.17 & $D x+T x$ & Yes (GA) & 160.33 & 8.98 \\
\hline 19 & $11, M$ & 7.7 & No & $\mathrm{H}$ & No & 604.73 & 1.27 & Dx & Yes (GA) & 104.80 & 5.87 \\
\hline 20 & $12, \mathrm{~F}$ & 3.1 & No & $\mathrm{H}$ & No & 1399.89 & 2.94 & $D x$ & Yes (CS) & 47.47 & 2.66 \\
\hline 21 & $4, \mathrm{M}$ & 1.6 & Yes (GA) & $\mathrm{H} \& \mathrm{~N}$ & No & 705.97 & 2.44 & $D x$ & Yes (GA) & 41.99 & 2.35 \\
\hline Mean & & 5.62 & & & & 762.38 & 2.26 & & & 119.37 & 6.68 \\
\hline SD & & 3.05 & & & & 300.75 & 1.00 & & & 117.85 & 6.60 \\
\hline
\end{tabular}

$\mathrm{CS}=$ conscious sedation; $\mathrm{Dx}=$ diagnostic; $\mathrm{GA}=$ general anesthesia; $\mathrm{H}=$ head (cerebral); $\mathrm{H} \& \mathrm{~N}=$ head and neck (cervicocerebral); $\mathrm{Tx}=$ treatment.

tween fe-SPGR and DSA ( $\mathrm{p}=0.146)$. Kruskal-Wallis and subsequent post hoc pairwise comparison tests of pooled scores of DC showed a significant difference among CTA, fe-SPGR, and DSA $(\mathrm{p}<0.001)$ as well as between pairs of the 3 groups: CTA and fe-SPGR $(\mathrm{p}=0.004)$, fe-SPGR and DSA $(p=0.043)$, and CTA and DSA $(p<0.001)$. Interrater agreement for score assignment was very good for LC and DC with fe-SPGR and DSA $(\kappa=0.86-1.0, \mathrm{p}<0.001)$ (Table 3). Interrater agreement for score assignment was very good for LC $(\kappa=0.87, \mathrm{p}<0.001)$ and good for DC ( $=0.77, \mathrm{p}<0.001)$ with CTA.

A total of 2 small aneurysms were identified by both readers (one a $2.5-\mathrm{mm}$ intranidal aneurysm and the other a 2-mm peri-nidal aneurysm) on CTA, but none were seen on fe-SPGR. Neither aneurysm was confirmed on DSA. DSA showed a 4-mm intranidal aneurysm in a different patient that was not identified by either reader on fe-SPGR or CTA.

\section{Discussion}

Our study showed that fe-SPGR allows for excellent visualization and comparable grading of AVMs relative to CTA and DSA. The high spatial resolution offered by fe-SPGR yields high scores of LC and DC, which were significantly higher (and with smaller standard deviations) with fe-SPGR than with CTA. While there was no significant difference in assigning grades between fe-SPGR and CTA, there was improved visual depiction of AVMs with fe-SPGR. In addition, there was very good interrater agreement for score assignment with fe-SPGR, similar to CTA and DSA.

Radiation exposure data for the image types in this study were $1.50 \mathrm{mSv}$ (mean effective dose) for head CTA, $2.73 \mathrm{mSv}$ for head and neck CTA, and $119.4 \mathrm{~Gy} \times \mathrm{cm}^{2}$ (DAP) and $6.68 \mathrm{mSv}$ for DSA. Our data are consistent with a previously reported effective dose range of head CT scans in children younger than 14 years: 1.1 to 3.5 $\mathrm{mSv}{ }^{29}$ Less is known about the radiation dose for pediatric DSA; however, in one study, the reported DAP range for cerebral DSA in children younger than 18 years was 3.8 to $23.2 \mathrm{~Gy} \mathrm{~cm}^{2} .{ }^{11}$ The mean DAP was higher in our study because some of the analyzed digital subtraction angiograms were obtained for a combination of diagnostic and treatment purposes. Our findings, therefore, suggest a potential role of fe-SPGR in the diagnostic evaluation of AVMs, which is important in the pediatric population given the risk of radiation exposure with CTA and DSA, especially when considering that most of these patients often undergo repeat surveillance imaging.

Prior studies in the literature have evaluated 3D contrast-enhanced TOF MRA using gadolinium-based con- 
TABLE 2. Cumulative contrast, sedation, and radiation exposure for each image modality during the study period

\begin{tabular}{|c|c|c|c|c|c|c|c|c|c|c|c|c|}
\hline \multirow[b]{2}{*}{$\begin{array}{l}\text { Case } \\
\text { No. }\end{array}$} & \multirow[b]{2}{*}{$\begin{array}{l}\text { Age } \\
\text { (yrs) }\end{array}$} & \multicolumn{3}{|c|}{ Cumulative fe-SPGR Exams } & \multicolumn{4}{|c|}{ Cumulative CTA Exams } & \multicolumn{4}{|c|}{ Cumulative Diagnostic/Surveillance DSA Exams } \\
\hline & & $\begin{array}{l}\text { Total } \\
\text { No. of } \\
\text { Exams }\end{array}$ & $\begin{array}{c}\text { Total } \\
\text { Contrast } \\
\text { Amount (ml) }\end{array}$ & $\begin{array}{c}\text { Total } \\
\text { No. of } \\
\text { Sedations }\end{array}$ & $\begin{array}{l}\text { Total } \\
\text { No. of } \\
\text { Exams }\end{array}$ & $\begin{array}{c}\text { Total } \\
\text { No. of } \\
\text { Sedations }\end{array}$ & $\begin{array}{l}\text { Total DLP } \\
(\mathrm{mGy} \times \mathrm{cm})\end{array}$ & $\begin{array}{c}\text { Total } \\
\text { Effective } \\
\text { Dose (mSv) }\end{array}$ & $\begin{array}{l}\text { Total } \\
\text { No. of } \\
\text { Exams }\end{array}$ & $\begin{array}{c}\text { Total } \\
\text { No. of } \\
\text { Sedations }\end{array}$ & $\begin{array}{l}\text { Total DAP } \\
\left(\mathrm{Gy} \times \mathrm{cm}^{2}\right)\end{array}$ & $\begin{array}{c}\text { Total } \\
\text { Effective } \\
\text { Dose }(\mathrm{mSv})\end{array}$ \\
\hline 1 & 14 & 5 & 23.9 & 0 & 2 & 0 & 1833.16 & 6.32 & 2 & 2 & 122.27 & 6.85 \\
\hline 2 & 13 & 5 & 25.2 & 0 & 1 & 0 & 673.03 & 1.41 & 1 & 1 & 101.52 & 5.69 \\
\hline 3 & 15 & 5 & 29.8 & 0 & 2 & 0 & 1991.33 & 4.18 & 3 & 3 & 178.55 & 10.00 \\
\hline 4 & 14 & 3 & 21.7 & $1(\mathrm{GA})$ & 1 & 0 & 492.59 & 1.03 & 3 & 3 & 276.64 & 15.49 \\
\hline 5 & 9 & 3 & 11.0 & 0 & 1 & 0 & 530.72 & 1.11 & 1 & 1 & 45.78 & 2.56 \\
\hline 6 & 24 & 5 & 31 & 0 & 1 & 0 & 834.33 & 2.88 & 1 & 1 & 56.17 & 3.15 \\
\hline 7 & 9 & 1 & 3.4 & $1(\mathrm{GA})$ & 1 & 0 & 898.51 & 3.10 & 1 & 1 & 13.50 & 0.76 \\
\hline 8 & 18 & 3 & 33.9 & 0 & 1 & 0 & 802.24 & 2.77 & 1 & 1 & 216.74 & 12.14 \\
\hline 9 & 22 & 6 & 31.9 & 0 & 1 & 0 & 898.51 & 3.10 & 2 & 2 & 259.62 & 14.54 \\
\hline 10 & 16 & 1 & 5.2 & 0 & 1 & 0 & 866.42 & 2.99 & 2 & 2 & 204.71 & 11.46 \\
\hline 11 & 8 & 3 & 11.3 & $3(\mathrm{GA})$ & 1 & 0 & 924.81 & 3.19 & 2 & 2 & 81.87 & 4.58 \\
\hline 12 & 11 & 4 & 15.3 & 0 & 1 & 0 & 738.06 & 2.55 & 1 & 1 & 184.32 & 10.32 \\
\hline 13 & 16 & 3 & 14.1 & 0 & 2 & 0 & 1858.83 & 6.41 & 1 & 1 & 94.24 & 5.28 \\
\hline 14 & 18 & 2 & 25.1 & 0 & 1 & 0 & 802.24 & 2.77 & 0 & & & \\
\hline 15 & 15 & 2 & 18.5 & 0 & 2 & 0 & 1346.33 & 4.64 & 1 & 1 & 54.03 & 3.03 \\
\hline 16 & 18 & 2 & 10.3 & 0 & 2 & 0 & 903.24 & 3.12 & 1 & 1 & 62.20 & 3.48 \\
\hline 17 & 4 & 3 & 7.3 & $3(\mathrm{GA})$ & 1 & 0 & 766.22 & 1.61 & 2 & 2 & 64.70 & 3.62 \\
\hline 18 & 12 & 2 & 6.8 & $2(\mathrm{GA})$ & 2 & 0 & 884.24 & 1.86 & 0 & & & \\
\hline 19 & 11 & 3 & 24.2 & 0 & 1 & 0 & 604.73 & 1.27 & 3 & 3 & 137.90 & 7.72 \\
\hline 20 & 12 & 5 & 17.1 & 0 & 2 & 0 & 2170.15 & 4.56 & 3 & 3 & 130.51 & 7.31 \\
\hline 21 & 4 & 3 & 5.6 & $3(\mathrm{GA})$ & 2 & 0 & 1411.94 & 4.87 & 2 & 2 & 167.77 & 9.40 \\
\hline Mean & & 3.29 & 17.73 & & 1.38 & & 1058.65 & 3.13 & 1.57 & & 129.11 & 7.23 \\
\hline SD & & 1.42 & 9.72 & & 0.50 & & 501.88 & 1.56 & 0.93 & & 75.79 & 4.24 \\
\hline
\end{tabular}

trast agents in the detection of AVMs. ${ }^{15,23,42}$ Heidenreich et al. found that TOF MRA following the intravenous administration of gadopentetate dimeglumine (Magnevist, Schering) offered superior characterization of AVM angioarchitecture at $3 \mathrm{~T}$ and $1.5 \mathrm{~T}$, but the image quality of both were still far from being equal to that of DSA. ${ }^{15}$ Lee et al. found that 3D post-gadoterate meglumine MRA had high sensitivity but low specificity for the detection of residual AVMs after treatment with radiosurgery. ${ }^{23}$ In contrast to these studies, the use of a 3D volumetric SGPR sequence following administration of a blood pool contrast agent provides for improved image quality and high spatial resolution. Specifically, the use of minimum repetition and echo times with the SPGR sequence in this study accentuated visualization of the vasculature by providing for more T1 weighting and a sharper and more detailed appearance of small vessels when compared with "standard clinical" SPGR parameters (slightly higher repetition and echo times) in which the brain parenchyma and graywhite matter contrast are emphasized.

Ferumoxytol, a second-generation ultrasmall superparamagnetic iron oxide nanoparticle with a mean diameter of less than $50 \mathrm{~nm}$, is characterized by high longitudinal and transverse relaxivity, which allows for improved image quality and lesion depiction. ${ }^{2,6}$ After intravenous injection, it circulates in the blood vessel lumen, temporarily escaping sequestration and phagocytosis by macrophages of the reticuloendothelial system. This phenomenon contributes to the relatively long half-life of ferumoxytol, allowing it to serve as an excellent blood pool agent during the first-pass and equilibrium phases of imaging. ${ }^{19}$ Ex-

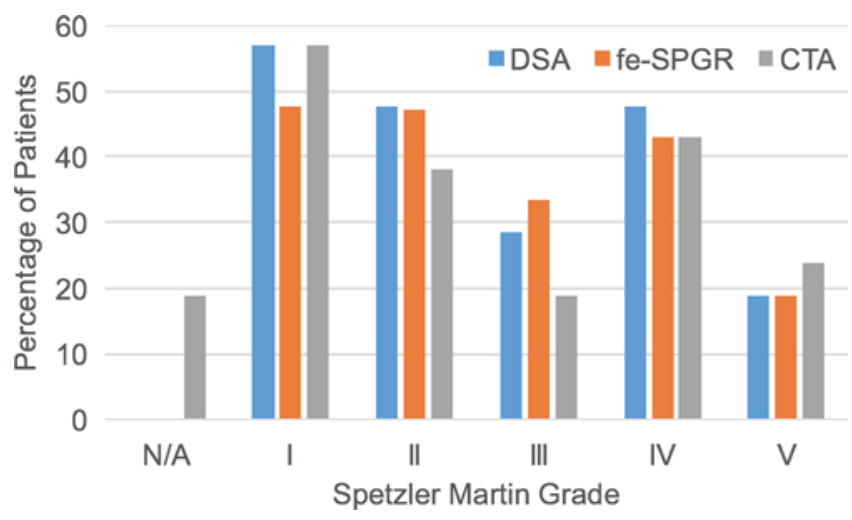

FIG. 2. Distribution and percentage of Spetzler-Martin graded AVMs on DSA, CE-MRA using ferumoxytol-enhanced SPGR (fe-SPGR), and CTA. Using pooled scores from all readers, no significant difference was found between assigned Spetzler-Martin grades between any of the three image groups $(p=0.991)$. N/A denotes lesions that could not be assigned a grade. Figure is available in color online only. 

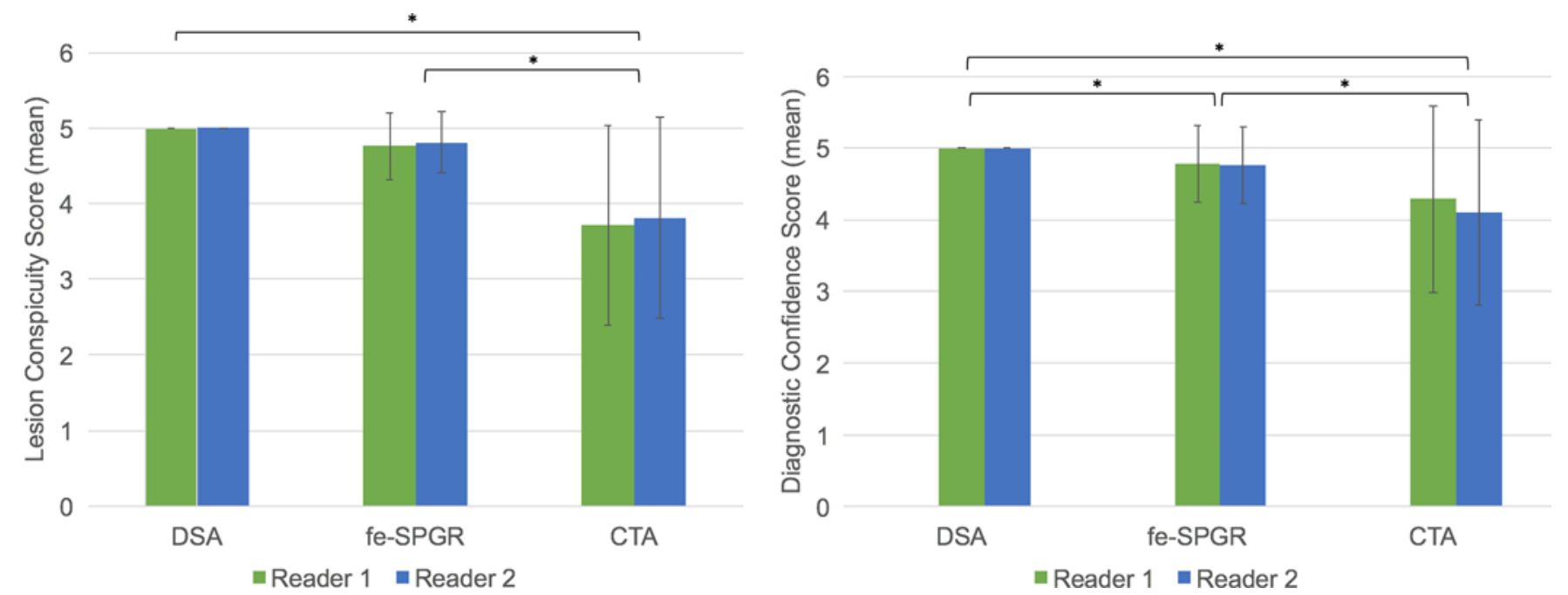

FIG. 3. Assessment of lesion conspicuity and diagnostic confidence scores using a 5-point Likert scale on DSA, CE-MRA using fe-SPGR, and CTA. Mean scores are shown, with the error bar representing the standard deviation. Left: Using pooled scores for lesion conspicuity, significant differences $\left(^{*}\right)$ were found between CTA and fe-SPGR $(p<0.001)$ and CTA and DSA $(p<0.001)$ but not between fe-SPGR and DSA ( $p=0.146)$. Right: Using pooled scores for diagnostic confidence, significant differences $\left({ }^{*}\right)$ were found between CTA and fe-SPGR $(p=0.004)$, fe-SPGR and DSA $(p=0.043)$, and CTA and DSA $(p<0.001)$. Figure is available in color online only.

amples of this include many studies outside of the central nervous system showing ferumoxytol's utility in cardiac, aortic, renal, and lower-extremity vascular imaging. ${ }^{9,12,35}$, ${ }^{36,38}$ In fact, as of today, ferumoxytol is the only blood pool contrast agent that is available for clinical use in humans following the discontinued manufacturing of gadofosveset trisodium (Ablavar, Lantheus Medical Imaging) in August 2016. Following administration, ferumoxytol is cleared by the reticuloendothelial system and not through the kidneys, making it relatively safe to use in patients with renal insufficiency. ${ }^{19}$

In 2009, ferumoxytol was approved by the US FDA for the treatment of iron deficiency anemia in adults with chronic kidney disease, ${ }^{24}$ making it widely available for clinical imaging through use as an off-label agent. However, a black box warning was issued by the FDA in 2015 concerning serious hypersensitivity reactions that occurred with ferumoxytol administration in adult patients with chronic renal insufficiency who were treated for iron deficiency anemia. Recommendations changing the prescription instructions to decrease the risk of serious allergic reactions were also included in the warning..$^{10}$ Despite these potential safety risks, ferumoxytol has a strong safety profile and has shown good tolerance for use in imaging in children and young adults, particularly to answer specific diagnostic questions. ${ }^{31,35,43}$ Two recent studies in neonates and young infants ( 1 day to $<2$ years) using ferumoxytol-enhanced cardiac MRI to evaluate congenital heart disease also reported no adverse reactions. ${ }^{21,33}$ To date, in the largest single-center report of safety for ferumoxytol use in MRI, Nguyen et al. evaluated 217 patients (ages 3 days to 94 years) with different renal function and indications and found that while 2 patients experienced ferumoxytol-related nausea, no cases of serious adverse events occurred..$^{34}$

The safety of repeated ferumoxytol dosing has yet to be fully established, but a retrospective study of ferumoxytol in 8666 dialysis-dependent patients, many of whom had repeat dosing, over a 1-year period showed low incidences of serious $(0.2 \%)$ and milder $(0.07 \%-1.77 \%)$ adverse events. ${ }^{37}$ Completion of a Phase IV randomized control trial of repeated ferumoxytol doses in 296 enrolled patients on hemodialysis is also expected soon..$^{25}$ In our study, no patients experienced any adverse reactions during the baseline feSPGR examination or during any follow-up fe-SPGR examinations during the study period (69 total ferumoxytol injections). In addition, based on postmarket surveillance, the risks of serious allergic and anaphylactic reactions with ferumoxytol are similar to those with ionic iodinated contrast agents and higher than those with nonionic iodinated and gadolinium-based contrast agents; however, risks of contrast-induced nephrotoxicity and nephrogenic systemic fibrosis in patients with severe kidney disease are higher with iodinated and gadolinium-based contrast agents, respectively, than with ferumoxytol. ${ }^{43}$ Another consideration with gadolinium exposure is its association with neuronal tissue deposition in patients with relatively normal kidney function, but the clinical significance of this finding is not yet known. ${ }^{28}$

Beyond the risk of anaphylactic reactions, there are potential issues of iron clearance from the body and iron accumulation in organs with the use of iron nanoparticles. Storey and Arbini found that the iron clearance rate in healthy individuals following ferumoxytol infusion ranged from 3 to 11 months, with higher R2* values found in the liver (relative to pre-ferumoxytol baseline values) in those with longer clearance times. ${ }^{41}$ However, the clinical significance of R2* values as they relate to iron overload is still unclear and needs further investigation. Certainly, radiologists and clinicians should be aware of the potential for prolonged signal alteration in the liver, spleen, and bone marrow that may last for months after initial feru- 
TABLE 3. Pooled mean scores with standard deviation and interrater agreement*

\begin{tabular}{|c|c|c|c|c|c|c|}
\hline & \multicolumn{2}{|c|}{ DSA } & \multicolumn{2}{|c|}{ fe-SPGR } & \multicolumn{2}{|c|}{ CTA } \\
\hline & Mean \pm SD & $\kappa$ & Mean \pm SD & $\kappa$ & Mean \pm SD & к \\
\hline SM grade & $2.6 \pm 1.3$ & $1.0(p<0.001)$ & $2.6 \pm 1.3$ & $0.94(p<0.001)$ & $2.7 \pm 1.5$ & $0.93(p<0.001)$ \\
\hline LC & $5.0 \pm 0$ & $1.0(p<0.001)$ & $4.8 \pm 0.4$ & $0.86(p<0.001)$ & $3.8 \pm 1.3$ & $0.87(p<0.001)$ \\
\hline $\mathrm{DC}$ & $5.0 \pm 0$ & $1.0(p<0.001)$ & $4.9 \pm 0.5$ & $1.0(p<0.001)$ & $4.2 \pm 1.2$ & $0.77(p<0.001)$ \\
\hline
\end{tabular}

${ }^{*}$ Expressed as Fleiss' kappa coefficient.

moxytol administration. In our experience, the T1 signal in the intracranial vasculature associated with ferumoxytol use typically disappeared within 1 week after infusion; as such, repeat vascular imaging (especially within a few days) is possible without the need for re-administration of additional contrast agent.

Given the detailed anatomical delineation offered by CE-MRA using fe-SPGR, especially in conjunction with other MRI sequences such as ASL, a noncontrast perfusion sequence that allows for the identification of abnormal arteriovenous shunting, ${ }^{18,22}$ patients with higher-grade AVMs may not need DSA for characterization of their lesions (thereby avoiding the risks of radiation exposure and potential procedural complications, including reducing the number of sedation events that are often required during DSA in pediatric patients), especially if stereotactic radiosurgery is the ultimate treatment of choice. Fe-SPGR may also potentially play an important role in assessing for residual or recurrent AVMs in previously treated patients. This is supported by the fact that Spetzler-Martin grades were assigned to $100 \%$ of patients with fe-SPGR and DSA but only $81 \%$ of patients with CTA. Marked artifact from prior embolization material obscuring visualization of the adjacent vessels was responsible for the difficulty in assigning grades in the $19 \%$ of patients with CTA. As an example, in one of our patients with a left temporal AVM who had previously been treated with Onyx and stereotactic radiosurgery (Fig. 4), residual AVM could not be assessed on CTA due to streak artifact from prior embolization material (Video 1).

VIDEO 1. Whole-brain CT angiogram showing marked obscuration of residual AVM in the left temporal lobe from embolization material in a 14-year-old female patient who was previously treated with Onyx and CyberKnife radiosurgery (same patient as in Fig. 4). Copyright Stanford University. Published with permission. Click here to view.

However, clear vascular abnormality was seen on the feSPGR image (Video 2) and associated with abnormal arteriovenous shunting on ASL imaging; subsequently, the presence of residual AVM was confirmed by DSA.

VIDEO 2. Whole-brain CE-MRA with fe-SPGR images showing abnormal vascularity in the left temporal lobe consistent with residual AVM in a 14-year-old female patient who was previously treated with Onyx and CyberKnife radiosurgery (same patient as in Fig. 4). Copyright Stanford University. Published with permission. Click here to view.

The fe-SPGR images were used for intraoperative navigation and allowed the surgeon to localize and completely remove the residual AVM.

There are additional benefits of using a contrast-enhanced 3D volumetric sequence tailored for vascular evaluation. One example is the ability to coregister the sequence with other imaging sequences, such as functional MRI (fMRI). The small residual AVM in the left parietal lobe of the patient in Fig. 5 was best seen on fe-SPGR. As such, this sequence was fused with images from an fMRI delineating speech activation (object-naming task in Fig. 5); the fused images clearly show Wernicke's area just anterior to the AVM. This information proved to be useful to the surgeon when planning for resection of this lesion. In addition, fe-SPGR including the fused images is compatible with surgical navigation software and has allowed for real-time intraoperative localization of AVMs at our institution. The high spatial detail of vessels provided by a contrast-enhanced 3D volumetric sequence also potentially allows for improved planning of radiosurgery treatment fields, given the excellent visualization of the nidus and surrounding vessels on MRI. ${ }^{16}$ Our institution now routinely uses fe-SPGR in all of our pediatric brain AVM patients for treatment planning and clinical surveillance, unless contraindicated by known iron allergy or documented adverse reaction to ferumoxytol.

One limitation of the study is the lack of dynamic imaging and temporal resolution information, which is a clear advantage of DSA. As many vessels are present on fe-SPGR due to its high spatial resolution, readers occasionally found it difficult to distinguish angiomatous vessels related to the nidus from adjacent normal vessels. Being able to visualize flow over time through these vessels could increase diagnostic confidence for detection of abnormal versus normal vasculature. In addition, identification of small intranidal and peri-nidal aneurysms proved to be difficult for readers, given the challenge of visualizing a small aneurysm in the background of numerous bright arteries and veins on each image slice of a series. This resulted in both readers missing a 4-mm intranidal aneurysm in a patient on CTA and fe-SPGR that was eventually seen on DSA. In addition, the 2 small aneurysms detected by both readers on CTA but not on fe-SPGR and DSA may have represented tiny focal areas of extravasation rather than true aneurysms. The future addition of dynamic contrast-enhanced imaging may aid in the detection of aneurysms on fe-SPGR, as arteries can be distinguished from veins during early-phase imaging and can potentially help to reduce the amount of background vessels present on an early-phase image. Another limitation is the small number of patients included during the defined study period. Future investigations are therefore needed to determine the short- and long-term clinical benefits of using fe-SPGR. Also, given the retrospective nature of this study, we only compared 3D CE-MRA using fe-SPGR with CTA. Comparison with gadolinium-enhanced MRA 

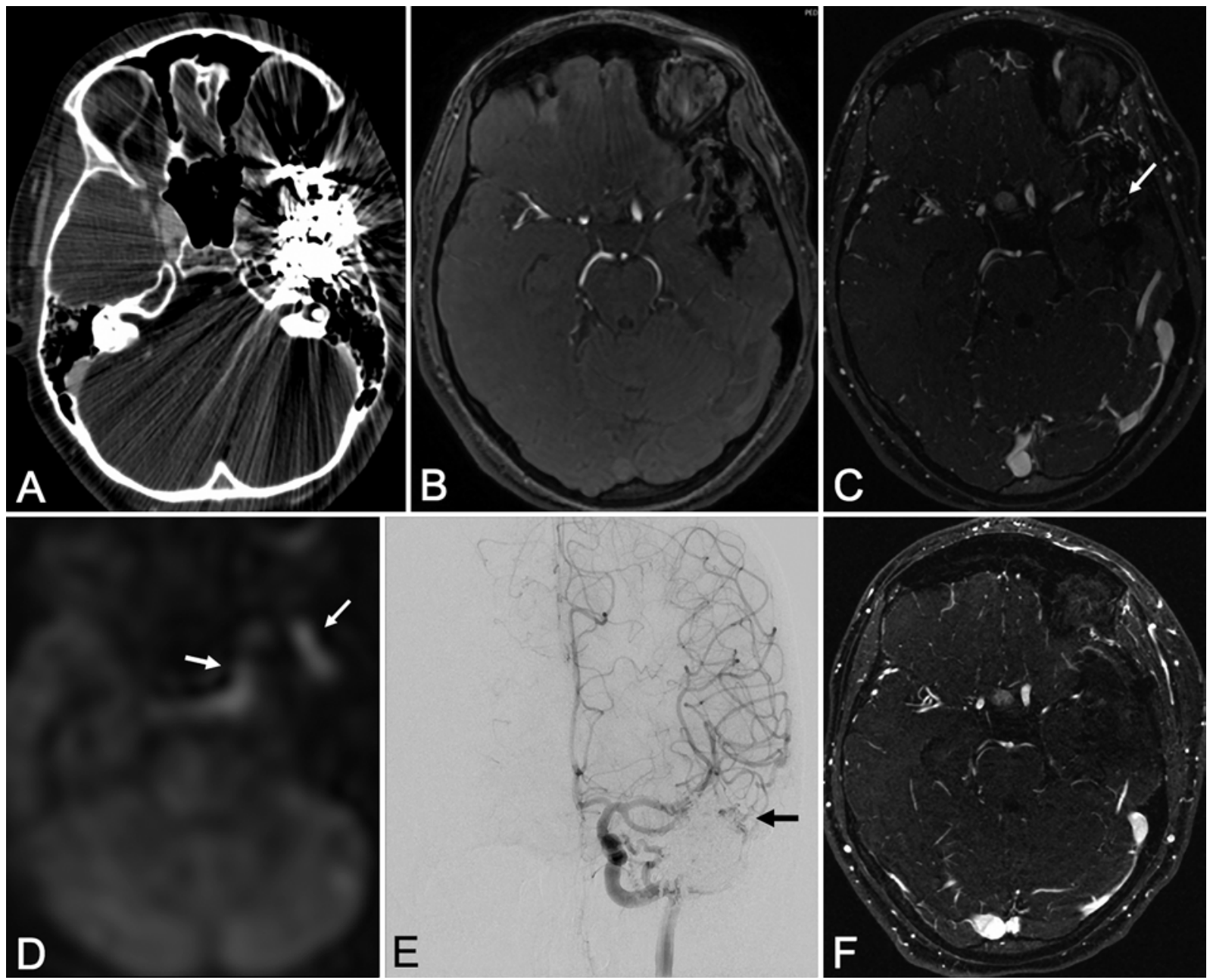

FIG. 4. Images obtained in a 14-year-old female patient with a left temporal AVM that was previously treated with Onyx and CyberKnife radiosurgery. A: CT angiogram showing marked artifact from prior Onyx embolization limiting evaluation for residual AVM. B: No residual AVM is detected on 3D noncontrast TOF MRA. C: Abnormal vascularity (arrow) is seen in the left temporal lobe on CE-MRA using fe-SPGR, concerning for residual AVM. D: ASL demonstrating an abnormal venous signal (arrows) in the region, consistent with arteriovenous shunting. E: Residual AVM (arrow) is confirmed on DSA. F: Following subsequent resection, there is no evidence of residual AVM on this fe-SPGR image. See videos of these images.
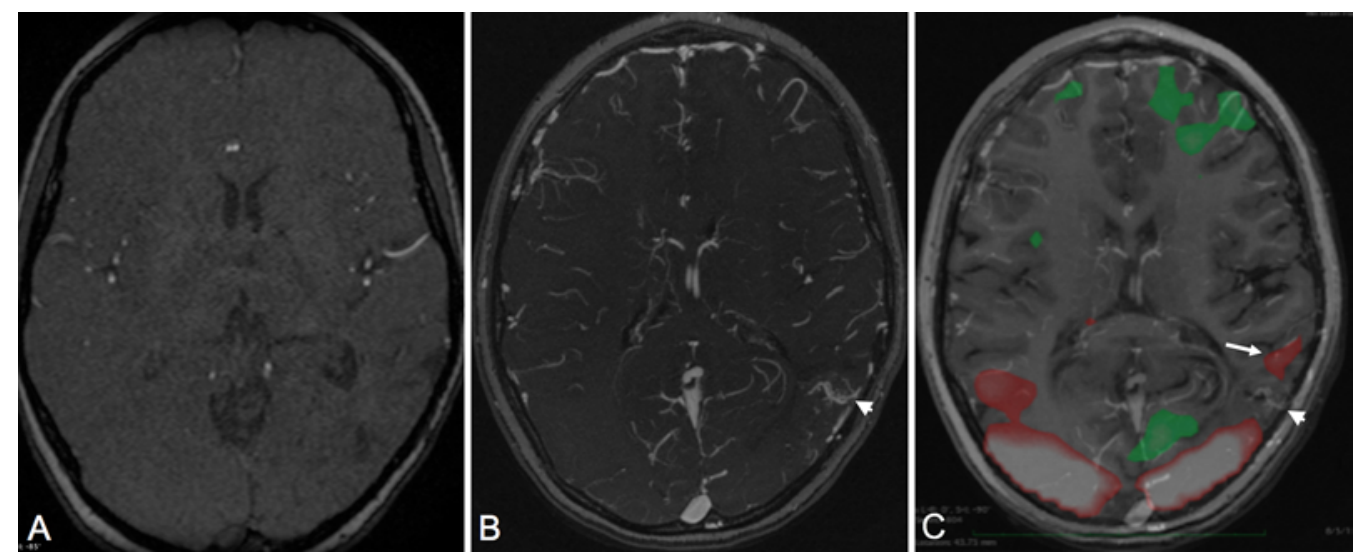

FIG. 5. Images obtained in a 14-year-old female patient with a residual left parietal AVM following prior resection, embolization, and CyberKnife radiosurgery. A: The residual AVM is not well seen on 3D noncontrast TOF MRA. B: Maximum intensity projection image of a CE-MRA using fe-SPGR showing an abnormal tangle of vessels in the left parietal lobe (arrowhead), concerning for residual AVM. C: Fused image from fe-SPGR and fMRI map (obtained during an object-naming task) showing activation of Wernicke's area (arrow) just anterior to the AVM (arrowhead). Image fusion was used to help guide resection of this vascular lesion. Figure is available in color online only. 
is important since this method is frequently used in clinical practice. However, this was not feasible in this study, as the use of 2 contrast agents for a single clinical MRI examination is not indicated. A prospective study comparing ferumoxytol-enhanced and gadolinium-enhanced MRA for the evaluation of cerebrovascular malformations is needed.

\section{Conclusions}

Contrast-enhanced MRA using fe-SPGR performed robustly in the diagnostic evaluation of AVMs, with comparable Spetzler-Martin grading relative to CTA and DSA. Although the percentage of graded AVMs was similar for all image types, scores for LC and DC were significantly higher with fe-SPGR than with CTA. Benefits for this imaging technique include improved visualization of AVMs in patients who previously underwent embolization, no risk of radiation exposure, ability to fuse with fMRI, and good compatibility with surgical navigation software. While there are some safety concerns with ferumoxytol use, published studies to date have shown ferumoxytol to be well tolerated for use in diagnostic imaging. Furthermore, it is now the only blood pool contrast agent that is available for clinical use. In the future, the addition of dynamic and phase contrast imaging to obtain temporal resolution, flow, and velocity information may provide additional noninvasive information regarding the structure, function, and physiology of an AVM. Fe-SPGR can also be considered for the surveillance of treated AVMs, which may obviate or lessen the need for invasive follow-up DSA (to potentially decrease overall radiation exposure) in certain clinical settings, such as in clinically stable patients, although further investigation is needed.

\section{Acknowledgments}

This work was supported by the National Institutes of Health (NIH) grant no. R01 EB009690.

\section{References}

1. Altman DG: Practical Statistics for Medical Research. Boca Raton: Chapman \& Hall/CRC, 1999

2. Benderbous $\mathrm{S}$, Corot C, Jacobs P, Bonnemain B: Superparamagnetic agents: physicochemical characteristics and preclinical imaging evaluation. Acad Radiol 3 (Suppl 2):S292S294, 1996

3. Blauwblomme T, Naggara O, Brunelle F, Grévent D, Puget S, Di Rocco F, et al: Arterial spin labeling magnetic resonance imaging: toward noninvasive diagnosis and follow-up of pediatric brain arteriovenous malformations. J Neurosurg Pediatr 15:451-458, 2015

4. Chalouhi N, Jabbour P, Magnotta V, Hasan D: The emerging role of ferumoxytol-enhanced MRI in the management of cerebrovascular lesions. Molecules 18:9670-9683, 2013

5. Chang W, Wu Y, Johnson K, Loecher M, Wieben O, Edjlali M, et al: Fast contrast-enhanced 4D MRA and 4D flow MRI using constrained reconstruction (HYPRFlow): potential applications for brain arteriovenous malformations. AJNR Am J Neuroradiol 36:1049-1055, 2015

6. Cotton F, Hermier M: The advantage of high relaxivity contrast agents in brain perfusion. Eur Radiol 16 (Suppl 7):M16-M26, 2006

7. Dósa E, Tuladhar S, Muldoon LL, Hamilton BE, Rooney
WD, Neuwelt EA: MRI using ferumoxytol improves the visualization of central nervous system vascular malformations. Stroke 42:1581-1588, 2011

8. Engelbrecht MR, Saeed M, Wendland MF, Canet E, Oksendal AN, Higgins CB: Contrast-enhanced 3D-TOF MRA of peripheral vessels: intravascular versus extracellular MR contrast media. J Magn Reson Imaging 8:616-621, 1998

9. Ersoy H, Jacobs P, Kent CK, Prince MR: Blood pool MR angiography of aortic stent-graft endoleak. AJR Am J Roentgenol 182:1181-1186, 2004

10. Food and Drug Administration: FDA Drug Safety Communication: FDA strengthens warnings and changes prescribing instructions to decrease the risk of serious allergic reactions with anemia drug Feraheme (ferumoxytol). FDA.gov. March 30, 2015. (https://www.fda.gov/Drugs/DrugSafety/ ucm440138.htm) [Accessed April 13, 2018]

11. Habib Geryes B, Bak A, Lachaux J, Ozanne A, Boddaert N, Brunelle F, et al: Patient radiation doses and reference levels in pediatric interventional radiology. Eur Radiol 27:39833990, 2017

12. Hadizadeh DR, Kukuk GM, Fahlenkamp UL, Pressacco J, Schäfer C, Rabe E, et al: Simultaneous MR arteriography and venography with blood pool contrast agent detects deep venous thrombosis in suspected arterial disease. AJR Am J Roentgenol 198:1188-1195, 2012

13. Hadizadeh DR, Kukuk GM, Steck DT, Gieseke J, Urbach H, Tschampa HJ, et al: Noninvasive evaluation of cerebral arteriovenous malformations by $4 \mathrm{D}$-MRA for preoperative planning and postoperative follow-up in 56 patients: comparison with DSA and intraoperative findings. AJNR Am J Neuroradiol 33:1095-1101, 2012

14. Hadizadeh DR, von Falkenhausen M, Gieseke J, Meyer B, Urbach H, Hoogeveen R, et al: Cerebral arteriovenous malformation: Spetzler-Martin classification at subsecondtemporal-resolution four-dimensional MR angiography compared with that at DSA. Radiology 246:205-213, 2008

15. Heidenreich JO, Schilling AM, Unterharnscheidt F, Stendel R, Hartlieb S, Wacker FK, et al: Assessment of 3D-TOFMRA at 3.0 Tesla in the characterization of the angioarchitecture of cerebral arteriovenous malformations: a preliminary study. Acta Radiol 48:678-686, 2007

16. Huang YJ, Hsu SW, Lee TF, Ho JT, Chen WF: Consistency between targets delineated by angiography, computed tomography, and magnetic resonance imaging in stereotactic radiosurgery for arteriovenous malformation. Stereotact Funct Neurosurg 95:236-242, 2017

17. Illies T, Forkert ND, Ries T, Regelsberger J, Fiehler J: Classification of cerebral arteriovenous malformations and intranidal flow patterns by color-encoded 4D-hybrid-MRA. AJNR Am J Neuroradiol 34:46-53, 2013

18. Iv M, Fischbein NJ, Zaharchuk G: Association of developmental venous anomalies with perfusion abnormalities on arterial spin labeling and bolus perfusion-weighted imaging. J Neuroimaging 25:243-250, 2015

19. Iv M, Telischak N, Feng D, Holdsworth SJ, Yeom KW, Daldrup-Link HE: Clinical applications of iron oxide nanoparticles for magnetic resonance imaging of brain tumors. Nanomedicine (Lond) 10:993-1018, 2015

20. Kukuk GM, Hadizadeh DR, Boström A, Gieseke J, Bergener $\mathrm{J}$, Nelles M, et al: Cerebral arteriovenous malformations at $3.0 \mathrm{~T}$ : intraindividual comparative study of 4D-MRA in combination with selective arterial spin labeling and digital subtraction angiography. Invest Radiol 45:126-132, 2010

21. Lai LM, Cheng JY, Alley MT, Zhang T, Lustig M, Vasanawala SS: Feasibility of ferumoxytol-enhanced neonatal and young infant cardiac MRI without general anesthesia. J Magn Reson Imaging 45:1407-1418, 2017

22. Le TT, Fischbein NJ, André JB, Wijman C, Rosenberg J, Zaharchuk G: Identification of venous signal on arterial spin 
labeling improves diagnosis of dural arteriovenous fistulas and small arteriovenous malformations. AJNR Am J Neuroradiol 33: $61-68,2012$

23. Lee KE, Choi CG, Choi JW, Choi BS, Lee DH, Kim SJ, et al: Detection of residual brain arteriovenous malformations after radiosurgery: diagnostic accuracy of contrast-enhanced three-dimensional time of flight MR angiography at 3.0 Tesla. Korean J Radiol 10:333-339, 2009

24. Lu M, Cohen MH, Rieves D, Pazdur R: FDA report: Ferumoxytol for intravenous iron therapy in adult patients with chronic kidney disease. Am J Hematol 85:315-319, 2010

25. Macdougall IC, Dahl NV, Bernard K, Li Z, Batyky A, Strauss WE: The Ferumoxytol for Anemia of CKD Trial (FACT) - a randomized controlled trial of repeated doses of ferumoxytol or iron sucrose in patients on hemodialysis: background and rationale. BMC Nephrol 18:117, 2017

26. Manninen AL, Isokangas JM, Karttunen A, Siniluoto T, Nieminen MT: A comparison of radiation exposure between diagnostic CTA and DSA examinations of cerebral and cervicocerebral vessels. AJNR Am J Neuroradiol 33:20382042, 2012

27. McCollough C, Cody D, Edyvean S, Geise R, Gould B, Keat N, et al: AAPM Report No. 96. The Measurement, Reporting, and Management of Radiation Dose in CT. College Park, MD: American Association of Physicists in Medicine, 2008 (https://www.aapm.org/pubs/reports/RPT_96.pdf) [Accessed April 4, 2018]

28. McDonald RJ, McDonald JS, Kallmes DF, Jentoft ME, Murray DL, Thielen KR, et al: Intracranial gadolinium deposition after contrast-enhanced MR imaging. Radiology 275:772782,2015

29. Miglioretti DL, Johnson E, Williams A, Greenlee RT, Weinmann S, Solberg LI, et al: The use of computed tomography in pediatrics and the associated radiation exposure and estimated cancer risk. JAMA Pediatr 167:700-707, 2013

30. Mnyusiwalla A, Aviv RI, Symons SP: Radiation dose from multidetector row CT imaging for acute stroke. Neuroradiology 51:635-640, 2009

31. Muehe AM, Feng D, von Eyben R, Luna-Fineman S, Link MP, Muthig T, et al: Safety report of ferumoxytol for magnetic resonance imaging in children and young adults. Invest Radiol 51:221-227, 2016

32. Nerva JD, Kim LJ, Barber J, Rockhill JK, Hallam DK, Ghodke BV, et al: Outcomes of multimodality therapy in pediatric patients with ruptured and unruptured brain arteriovenous malformations. Neurosurgery 78:695-707, 2016

33. Nguyen KL, Han F, Zhou Z, Brunengraber DZ, Ayad I, Levi DS, et al: 4D MUSIC CMR: value-based imaging of neonates and infants with congenital heart disease. J Cardiovasc Magn Reson 19:40, 2017

34. Nguyen KL, Yoshida T, Han F, Ayad I, Reemtsen BL, Salusky IB, et al: MRI with ferumoxytol: a single center experience of safety across the age spectrum. J Magn Reson Imaging 45:804-812, 2017

35. Ning P, Zucker EJ, Wong P, Vasanawala SS: Hemodynamic safety and efficacy of ferumoxytol as an intravenous contrast agents in pediatric patients and young adults. Magn Reson Imaging 34:152-158, 2016

36. Prince MR, Zhang HL, Chabra SG, Jacobs P, Wang Y: A pilot investigation of new superparamagnetic iron oxide (ferumoxytol) as a contrast agent for cardiovascular MRI. J XRay Sci Technol 11:231-240, 2003

37. Schiller B, Bhat P, Sharma A: Safety and effectiveness of ferumoxytol in hemodialysis patients at 3 dialysis chains in the United States over a 12-month period. Clin Ther 36:7083, 2014

38. Sigovan M, Gasper W, Alley HF, Owens CD, Saloner D: USPIO-enhanced MR angiography of arteriovenous fistulas in patients with renal failure. Radiology 265:584-590, 2012

39. Soize S, Bouquigny F, Kadziolka K, Portefaix C, Pierot L: Value of 4D MR angiography at 3T compared with DSA for the follow-up of treated brain arteriovenous malformation. AJNR Am J Neuroradiol 35:1903-1909, 2014

40. Spetzler RF, Martin NA: A proposed grading system for arteriovenous malformations. J Neurosurg 65:476-483, 1986

41. Storey P, Arbini AA: Bone marrow uptake of ferumoxytol: a preliminary study in healthy human subjects. J Magn Reson Imaging 39:1401-1410, 2014

42. Unlu E, Temizoz O, Albayram S, Genchellac H, Hamamcioglu MK, Kurt I, et al: Contrast-enhanced MR 3D angiography in the assessment of brain AVMs. Eur J Radiol 60:367-378, 2006

43. Vasanawala SS, Nguyen KL, Hope MD, Bridges MD, Hope TA, Reeder SB, et al: Safety and technique of ferumoxytol administration for MRI. Magn Reson Med 75:2107-2111, 2016

\section{Disclosures}

Dr. Alley: clinical or research support for this study from GE Medical, and direct stock ownership in Arterys.

\section{Author Contributions}

Conception and design: Iv, Vasanawala, Alley, Moseley, Holdsworth, Cheshier, Yeom. Acquisition of data: Iv, Choudhri, Dodd, Vasanawala, Alley, Moseley, Holdsworth, Cheshier, Yeom. Analysis and interpretation of data: Iv, Holdsworth, Cheshier, Yeom. Drafting the article: Iv. Critically revising the article: all authors. Reviewed submitted version of manuscript: all authors. Approved the final version of the manuscript on behalf of all authors: Iv. Statistical analysis: Iv, Holdsworth. Administrative/technical/ material support: Iv, Grant, Cheshier, Yeom. Study supervision: Iv, Cheshier, Yeom.

\section{Supplemental Information \\ Videos}

Video 1. https://vimeo.com/262391367.

Video 2. https://vimeo.com/262391435.

\section{Previous Presentations}

A portion of this work was previously presented (as an oral presentation) at the 54th Annual Meeting of the American Society of Neuroradiology, Washington DC, April 2016.

\section{Correspondence}

Michael Iv: Stanford University Medical Center, Stanford, CA. miv@stanford.edu. 